\title{
The butterfly community assemblage of Mowire Quarry Site in the forest agroecological zone of Ghana: Response of indicator biodiversity to ongoing quarry operations.
}

\author{
Sampson Addae ${ }^{1}$, Sampson Addae ${ }^{2}$, Michael Osae ${ }^{3}$, Danilo Harms ${ }^{4}$, Jones Quartey ${ }^{1}$, Roger \\ Sigismund Anderson ${ }^{1}$, and Ben Aikins ${ }^{1}$ \\ ${ }^{1}$ University of Ghana \\ ${ }^{2}$ Affiliation not available \\ ${ }^{3}$ Biotechnology and Nuclear Agriculture Research Institute, Ghana Atomic Energy \\ Commission. \\ ${ }^{4}$ Universität Hamburg
}

November 25, 2020

\begin{abstract}
Quarry operations cause serious environmental impact on invertebrate communities and contribute negatively to habitat destruction and the species they promote but very little is still known about the response of butterflies to such disturbances in western Africa. The current study provides data from a baseline survey of butterflies at Mowire quarry site in the agroecological zone of Ghana and investigates the effects of ongoing quarry operations on butterfly diversity. Specifically quarry operations were assessed on species abundance and richness. A total of 417 individual butterflies belonging to 67 species from 5 families was recorded in three zones. High relative abundance in the Eastern Zone (EZ) $(\mathrm{N}=329)$ and high species richness $(\mathrm{S}=$ 55) may be due to increased flowering plants diversity which contain sweet nectar which attracts and support rich butterfly abundance. Low species richness $(\mathrm{S}=22)$ and relative abundance $(\mathrm{N}=41)$ in the Western Zone (WZ), and Northern Zone (NZ) $(\mathrm{S}=21)$ and low relative abundance $(\mathrm{N}=47)$, was corroborated with low plant diversity. Our results shows that, the EZ received less negative impact from the quarry operations but the operations negatively affected WZ and NZ. More generally our study indicates that state institutions should ensure mandatory environmental impact assessment reports from the quarry companies.
\end{abstract}

\section{Introduction}

Resource extraction through mining, lumbering, and quarry operations contribute to the economic lifeblood of many countries in Sub-Sahara Africa. Quarry operations are a major source of livelihood in the Mowire community, with a growing demand for limestone has led to the establishment of different scales of quarry companies in the district. Quarry operations have serious environmental impact on invertebrate communities and contribute negatively to habitat destruction and the species they promote. (Lameed, 2010). One of the greatest adverse environmental effect of quarry operation is the loss of species diversity (Anand, 2006). Insect biodiversity tends to provide clearer outcomes on ecological consequences of human-induced disturbance (Husseini, Abubakar, \& Nasare, 2019). Arthropods are useful bio indicators of environmental modifications caused by anthropogenic disturbance such as pollution, habitat fragmentation, loss of habitat and early warnings of ecological change. Butterflies provide information on the health of ecosystem through species presence-absence and abundance data, hence they are used as bio indicator to monitor changes in habitat condition in the environment (Weisser \& Siemann, 2008). The level of land degradation caused by stone quarry in Ghana has put forth questions as to whether or not the activity should be allowed to 
continue (Nartey, Nanor, \& Klake, 2012). Changes in landscape affect invertebrates more significantly and rapidly compared to other taxa. One of the greatest adverse environmental effect of quarry operations is the harm to biodiversity (Eta, Idiku, \& Dan, 2019). Diversity and abundance of butterfly species can be used to assess the impact of anthropogenic activities on landscape changes, rapid biodiversity assessment, monitoring degraded land and managed ecosystem (Gandhi, Patel, \& Padate, 2017). This study provides a baseline survey of butterfly abundance, diversity and species richness between three zones on the Mowire quarry site. Specifically the study sought to: i) to use butterflies as indicator species to assess the relationship between quarry operations and insect diversity in the quarry operational area. : ii) to assess the relationship between quarry operations and butterfly diversity and abundance between three zones of the quarry site. The Mowire Quarry site is perfect for carrying out this study due to the continuous quarry operations in the area and the large concession it holds.

\section{Materials and Methods}

Study Area

The research was conducted in Mowire near Kodie in the Ashanti Region of Ghana. An area lying between Latitude: $6^{\circ} 48^{\prime} 21.38^{\prime \prime}\left(6.8347^{\circ}\right)$ north and Longitude: $1^{\circ} 38^{\prime} 25.43^{\prime \prime}\left(1.7172^{\circ}\right)$ west with an elevation of $280 \mathrm{~m}$ in the Afigya Kwabre District (Fig 1). Average temperatures ranged between $25.0^{\circ} \mathrm{C}$ between July and August and $28.0^{\circ} \mathrm{C}$ from March to April with an average annual rainfall of $1400 \mathrm{~mm}$ (Bannerman et al .,2013). The district experiences relatively high humidity ranging from $90 \%$ to $98 \%$ in the rainy season and drops to below $75 \%$ in the dry season (Bannermanet al .,2013). The district has a current population density of 397.3 persons per square kilometer with increasing demand of land for residential purposes whiles available land for agriculture and natural vegetation has been depleted. The forest vegetation has been degraded by lumbering, settlement development and agriculture. Part of the forest has been disturbed by various human activities such as farming, logging and quarry operations. The economy of the district is mainly agrarian employing about $61 \%$ of the total workforce. K.K quarry and Brosa Mineral Resource Limited are located at Mowire Township about $(6 \mathrm{~km})$ away from Kodie on the Offinso highway. These two companies mine within the enclave of the quarry located in the town periphery. The quarry operation has existed and been active for the past fourteen years. Stone quarry is the main activity engaged by the two quarry companies. The stones are crushed into relatively small pieces of gravel-sized particles which are transported by heavy duty vehicles daily. Blasting of rocks are done every Tuesday and Friday. KK Quarry company take their turn to blast on Tuesdays whiles Brosa Mineral Resource blast on Fridays. The site was positioned on a radial map with three cardinal points Northern Zone (NZ), Eastern Zone (EZ) and Western Zones (WZ) (Figure1). Significant quarrying activities are undertaken on the (EZ) of the quarry operational which consist mainly of a secondary forest (dense canopy with a lot of undergrowth and sweet nectar plants) stretching along to the Northern part of the quarry. The EZ had the rock cracker which was a compact, cost-effective and transportable piece of machinery used to split, break stones and rock blocks, to reduce rocks and to split reinforced concrete. Crushing of stones into small pieces of rocks were done here. The rock cracker works almost every day for 24 hours generating a lot of noise and small volumes of dust to the adjoining environment. The (WZ) has two secondary forest (degraded with less canopy) patches as well as a sacred grove. The zone has a vast land which has been degraded by a lot of flying rocks from the quarry operations. Dust moves in this direction after every blast of the quarry which was done every Tuesday and Friday. The (NZ) comprises of a secondary forest and a settlement forming a large community and experiences a lot of land vibrations as a result of heavy vehicles which transport rock particles from the quarry site. The study was carried out between the months of August 2018 and February 2019, which spanned within dry and wet season.

\section{Sampling Method and species identification}

Sampling was carried out using a combination of aerial/butterfly net, random walk and count and Charaxes trap. Direct count of individuals were recorded along all the three zones and random walk sampling involving two individuals were employed during each visit throughout the sampling period. Four Charaxes traps $(90 \mathrm{~cm}$ in height), meant to attract alcohol-loving species or those attracted to fermenting fruits were set randomly 
(200m apart) to avoid bias in each zone during the sampling period (Figure1). Aerial/butterfly net was also used to capture butterflies, especially those which were not easily identifiable in flight. The net was swung swiftly around butterflies in flight. The Charaxes traps were retrieved every six days between 7:00am and 10:00am for catches and reset throughout the sampling period, complementing it with random walk and count in each zone. Trapped butterflies were killed by pinching the thorax gently, but firmly and placed in labelled envelopes for morphological identification in the lab. Butterflies were identified to species level with reference to the collection at the Entomology Museum at Department of Animal Biology and Conservation Science, University of Ghana. Floral density and diversity in each zone was visually identified and counted.

\section{Data Analysis}

Statistical analysis on species richness, species abundance, evenness, species diversity and habitat similarities or differences in all the zones were examined and computed. Data from all the zones were pooled to obtain total diversity of insects for the entire study site and sampling period. Three diversity indices were computed using PRIMER 6 \& PERMANOVA+ to compare data from all three zones. These were preferred because they allowed for qualitative assessment of sites by comparing their diversity indices (Chao et al. , 2005) which were treated for biodiversity assessment (Marshall et al ., 2006). Diversity indices (Margalef index, Shannon-index, Simpson index and Evenness) were calculated and compared between all three zones.

1. Species richness (Margalef): $d=(S-1) / \log (N)$ - This is a measure of the number of species present, making some allowance for the number of individuals.

2. Pielou's evenness: $J=\frac{H^{\prime}}{\operatorname{In}(S)}$ - this is a measure of equitability, a measure of how evenly the individuals are distributed among the different species

3. Shannon-Wiener index: $H=-\Sigma$ pi $\ln (p i)$ - incorporates both species richness and equitability components.

4. Simpson index (D): It is influenced by dominant species (Measures dominance and evenness).

$\mathrm{ni}=$ the number of individual species in the sample, $\Sigma n i=N . p i=$ the proportion of individual species in the sample, $p i=n i / N$. S=the number of species in the sample, $\mathrm{N}=$ the total number of individuals in the sample.

\section{Results and Discussion}

\section{Relative abundance of butterflies in all the three zones}

A total of 417 individuals belonging to 68 species from 5 families were collected from all the three zones. (Table 1). The main families included Nymphalidae (45 species, 106 individuals), Papilionidae (2 species, 21 individuals), Pieridae (14 species, 123 individuals), Hesperiidae (4 species, 17 individuals) and Lycaenidae (3 species, 150 individuals). At the family level Papilionidae and Hesperiidae had the lowest number of individuals while Lycaenidae had the highest number of individuals (Table 1).

\section{Diversity indices of butterflies in all the three zones}

The eastern zone (EZ) was the most diverse site for butterflies, with the highest relative abundance of individuals $(\mathrm{N}=329)$ and the highest species richness $(\mathrm{S}=55)$, which was corroborated with the highest Margalef index $(\mathrm{d}=9.317)$ with a Shannon Weiner index $\left(\mathrm{H}^{\prime}=2.616\right)$ (Table 2$)$. Two families Lycaenidae and Pieridae had the highest relative abundance of individuals (42.9\% and 30.7\%) (Table 1).

The western zone (WZ) had low species richness $(\mathrm{S}=22)$ and the lowest relative abundance of individuals $(\mathrm{N}=41)$ with the highest Shannon Weiner index $\left(\mathrm{H}^{\prime}=2.807\right)$ corroborated by the highest Pielou evenness $(\mathrm{J}=0.908)$ (Table 2$)$. Family Nymphalidae accounted for $61 \%$ of all the butterflies recorded in this zone (Table 1). 
The Northern zone (NZ) had the lowest species richness $(\mathrm{S}=21)$ as well as low relative abundance of individuals $(\mathrm{N}=47)$ corroborated by the lowest Margalef index $(\mathrm{d}=5.195)$ with a Shanon Weiner index $\left(H^{\prime}=2.696\right)$ (Table 2). Family Pieridae and Nymphalidae had the highest relative abundance of individuals $(34.0 \%)$ and $(32.0 \%)$ respectfully for all the butterflies recorded in this zone.

\section{Relative abundance of plant species in all the zones}

A total of 386 individuals belonging to 25 genera were identified across all the three zones for the sampling period. The Eastern zone had highest relative abundance of individuals $(\mathrm{N}=175)$ followed by the Western zone $(\mathrm{N}=111)$ and the least from the Northern zone $(\mathrm{N}=100)$.

\section{Diversity indices of plant species in all the three zones}

The eastern zone (EZ) had the highest relative abundance individuals $(\mathrm{N}=175)$ and the highest richness $(\mathrm{S}$ $=16)$. The western zone $(\mathrm{WZ})$ had low richness $(\mathrm{S}=13)$ and the highest Shannon Weiner index $\left(\mathrm{H}^{\prime}=2.241\right)$ (Table 4). The Northern zone (NZ) had the lowest richness $(\mathrm{S}=13)$ and the lowest relative abundance of individuals $(\mathrm{N}=100)$ (Table 4).

\section{Butterfly similarity index}

This shows the similarity between the Eastern and Northern zone at $39.81 \%$ and similarity between Eastern, Western and Northern Zone at $27.74 \%$. From the dendrogram all the Zones are dissimilar since their percentages fall below 50\% with Western and Northern Zones being more dissimilar.

The highest relative abundance $(\mathrm{N}=329)$ and species richness (55 species, 5 families) of butterflies in the (EZ) may be attributed to the presence of large undisturbed secondary forest which serves as a refuge for butterfly species. This was in consonance with work done by Tudor et al. (2004) which suggest that vegetation structure is important for butterfly assemblage as a site for mating and thermoregulation. This correlated positively with the highest abundance of tree species (175) and tree diversity (2.17292) in the EZ. This conforms to work done by Wala et al. (2012) which suggests that diverse nature of plant species in forest ecosystem attract butterflies for foraging and reproductive purposes, which could result in higher species richness and abundance.

Low species richness $(\mathrm{S}=22)$ and the lowest relative abundance $(\mathrm{N}=41)$ of butterflies in WZ could be attributed to the movement of dust particles towards the zone after every blast of the quarry. This is in agreement with work done by Mabogunje (2008) who suggested that, quarrying carries the potential of destroying habitats and the species they support. Dust and vibrations from heavy vehicles that transport quarry products in the NZ could possibly have caused the decline in butterfly relative abundance $(\mathrm{N}=47)$ and species richness $(S=21)$. This support work done by Nisic (2018), who indicated that quarry operations negatively affects the environment in a variety of ways during exploration, blasting, transportation and disposal of waste rocks.

\section{Conclusion}

Loss of suitable or quality habitats negatively affect the distribution and abundance of butterflies in the quarry enclave. The quarry operations had little effect on the diversity, abundance and richness of butterflies in the EZ and retained a suitable environment for insect diversity. However the quarry operations negatively affected WZ and NZ resulting in the lowest abundance of individuals and species richness. It is recommended that interventions to prevent biodiversity habitat loss in and around the quarry operational site should focus on policies that ensure and enforce the establishment of a dust control mechanism system in the extractive industry.

\section{Acknowledgements.}

We thank the chief and people of Mowire for giving us access to the community for the research. Special thanks goes to DAAD and ARPPIS. 
Data Availability Statement : The data that support the findings of this study are available at https://doi.org/10.5061/dryad.0vt4b8gxb.

\section{References}

Addo-Fordjour, P., \& Rahmad, Z. B. (2015). Environmental factors associated with liana community assemblages in a tropical forest reserve, Ghana. Journal of Tropical Ecology, 31 (1), 69-79.

Anand, N. (2006). Planning networks: Processing India's national biodiversity strategy and action plan.

Bannerman, S., Jnr, O. E., Duker, A., \& Yevugah, L. Environmental Noise Implications of Quarrying at Buoho Township and Surrounding Communities in Ghana.

Brehm, J. M., Saifan, S., Taifour, H., Abulaila, K., Al-Assaf, A., El-Oqlah, A., . . . Haddad, N. (2016). 15 Crop Wild Relatives: A Priority in Jordan? Developing a National Strategy for the Conservation of Plant Diversity in Jordan Using a Participatory Approach. Enhancing crop genepool use: Capturing wild relative and landrace diversity for crop improvement, 172.

Brown Jr, K. S., \& Hutchings, R. W. (1997). Disturbance, fragmentation, and the dynamics of diversity in Amazonian forest butterflies. Tropical forest remnants: ecology, management, and conservation of fragmented communities. University of Chicago Press, Chicago, 632 .

Chao, A., Chazdon, R. L., Colwell, R. K., \& Shen, T. J. (2005). A new statistical approach for assessing similarity of species composition with incidence and abundance data.Ecology letters, 8 (2), 148-159.

Degtjarenko, P. (2016). Impacts of alkaline dust pollution on biodiversity of plants and lichens: from communities to genetic diversity. In: Tartu.

Gehring, T. M., \& Swihart, R. K. (2003). Body size, niche breadth, and ecologically scaled responses to habitat fragmentation: mammalian predators in an agricultural landscape.Biological conservation, 109 (2), 283-295.

Honda, K., \& Kato, Y. (2005). Biology of butterflies. eds. Honda K and Kato Y, University of Tokyo Press, Tokyo, 255-301.

Iqbal, M. Z., Shafiq, M., \& Syed, K. A. (2001). Toxic effects of lead and cadmium individually and in combination on germination and growth of Leucaena leucocephala (Lam.) De-Wit. Pak. J. Bot, 33 , 551557.

Kyerematen, R., Adu-Acheampong, S., Acquah-Lamptey, D., Andersen, R., Owusu, E. H., \& Mantey, J. (2018). Butterfly diversity as indicator for environmental health within Tarkwa Gold Mine, Ghana. Environment and Natural Resources Research, 8, 69-83. DOI: 10.5539/enrr. v8n3p6 9 .

Kyerematen, R., Akuamoah-Boateng, A., Acquah-Lamptey, D., \& Anderson, R. (2014). Land use type affects butterfly diversity: a case study of the university of ghana, main campus, Legon. Journal of Biodiversity and Environmental Sciences, 5 (5), 205-214.

Lameed, G., \& Ayodele, A. (2010). Effect of quarrying activity on biodiversity: Case study of Ogbere site, Ogun State Nigeria. African Journal of Environmental Science and Technology, 4 (11), 740-750.

Larson, T. (1997). Butterflies of West African-Origin. Natural history, diversity, and conservation Draft Systematic part LARSON-CD-ROM, Monila, 395-399.

Lee, C. M., Park, J. W., Kwon, T.-S., Kim, S.-S., Ryu, J. W., Jung, S. J., \& Lee, S. K. (2015). Diversity and density of butterfly communities in urban green areas: an analytical approach using GIS. Zoological Studies, $54(1), 4$.

Lodh, R., \& Agarwala, B. (2016). Rapid assessment of diversity and conservation of butterflies in Rowa Wildlife Sanctuary: An Indo-Burmese hotspot-Tripura, NE India. Tropical Ecology, 57 (2), 231-242. 
Louis, A.-W. (2008). Mapping distribution of butterflies in central Bobiri Forest Reserve and investigation of logging and stage of regeneration on butterfly species richness and diversity.

Maleque, M. A., Maeto, K., \& Ishii, H. T. (2009). Arthropods as bioindicators of sustainable forest management, with a focus on plantation forests. Applied entomology and zoology, 44 (1), 1-11.

Maponga, O., \& Munyanduri, N. (2001). Sustainability of the dimension stone industry in Zimbabwechallenges and opportunities. Paper presented at the Natural resources forum.

Marks, K., \& Pullin, R. (1998). TOPILOT: Overall project evaluation and monitoring report. In: EFECOT, Brussels.

Moranz, R. A., Debinski, D. M., McGranahan, D. A., Engle, D. M., \& Miller, J. R. (2012). Untangling the effects of fire, grazing, and land-use legacies on grassland butterfly communities. Biodiversity and Conservation, 21 (11), 2719-2746.

Murugesan, M., Arun, P., \& Prusty, B. (2013). The butterfly community of an urban wetland system-a case study of Oussudu Bird Sanctuary, Puducherry, India. Journal of Threatened Taxa, 5 (12), 4672-4678.

Nganso, T., Kyerematen, R., \& Obeng-Ofori, D. (2012). Review of biodiversity in sacred groves in Ghana and implications on conservation. Current Trends in Ecology, $3,1-10$.

Padhye, A., Dahanukar, N., Paingankar, M., Deshpande, M., \& Deshpande, D. (2006). Season and landscape wise distribution of butterflies in Tamhini, northern Western Ghats, India. Zoos' Print Journal, 21 (3), 2175-2181.

Perrins, C. (1991). Tits and their caterpillar food supply. Ibis, 133 , 49-54.

Price, P. W. (1997). Insect ecology : John Wiley \& Sons.

Richardson, P. J., Lundholm, J. T., \& Larson, D. W. (2010). Natural analogues of degraded ecosystems enhance conservation and reconstruction in extreme environments.Ecological Applications, 20 (3), 728-740.

Saha, S. K., Nair, P. R., Nair, V. D., \& Kumar, B. M. (2009). Soil carbon stock in relation to plant diversity of homegardens in Kerala, India. Agroforestry systems, 76 (1), 53-65.

Saket, M., Branthomme, A., \& Piazza, M. (2010). FAO NFMA - support to developing countries on national forest monitoring and assessment. National forest inventories - pathways for common reporting. Edited by Springer, 583-594.

Sant'Anna, C. L., Ribeiro, D. B., Garcia, L. C., \& Freitas, A. V. (2014). Fruit-feeding butterfly communities are influenced by restoration age in tropical forests.Restoration Ecology, 22 (4), 480-485.

Santhosh, S., \& Basavarajappa, S. (2017). Biology of few butterfly species of agriculture ecosystems of arid regions of Karnataka, India. Research Journal of Life Sciences, Bioinformatics, Pharmaceutical and Chemical Sciences, 2 (6), 1-19.

Simonson, S. E., Opler, P. A., Stohlgren, T. J., \& Chong, G. W. (2001). Rapid assessment of butterfly diversity in a montane landscape. Biodiversity \& Conservation, 10 (8), 1369-1386.

Sourakov, A., Duehl, A., \& Sourakov, A. (2012). Foraging behavior of the blue morpho and other tropical butterflies: the chemical and electrophysiological basis of olfactory preferences and the role of color. Psyche: A Journal of Entomology, 2012.

Suggitt, A. J., Stefanescu, C., Paramo, F., Oliver, T., Anderson, B. J., Hill, J. K., . . . Thomas, C. D. (2012). Habitat associations of species show consistent but weak responses to climate. Biology Letters, 8 (4), 590-593.

Summerville, K. S., \& Crist, T. O. (2001). Effects of experimental habitat fragmentation on patch use by butterflies and skippers (Lepidoptera). Ecology, 82 (5), 1360-1370. 
Tudor, O., Dennis, R., Greatorex-Davies, J., \& Sparks, T. (2004). Flower preferences of woodland butterflies in the UK: nectaring specialists are species of conservation concern. Biological conservation, 119 (3), 397-403.

Vitousek, P. M., Mooney, H. A., Lubchenco, J., \& Melillo, J. M. (1997). Human domination of Earth's ecosystems. Science, 277 (5325), 494-499.

Wala, K., Woegan, A. Y., Borozi, W., Dourma, M., Atato, A., Batawila, K., \& Akpagana, K. (2012). Assessment of vegetation structure and human impacts in the protected area of A ledjo (T ogo). African Journal of Ecology, 50 (3), 355-366.

Yoon, J.-H., Kang, S.-J., Lee, J.-S., \& Oh, T.-K. (2006). Brevundimonas terrae sp. nov., isolated from an alkaline soil in Korea. International journal of systematic and evolutionary microbiology, 56 (12), 2915-2919.

Figures:

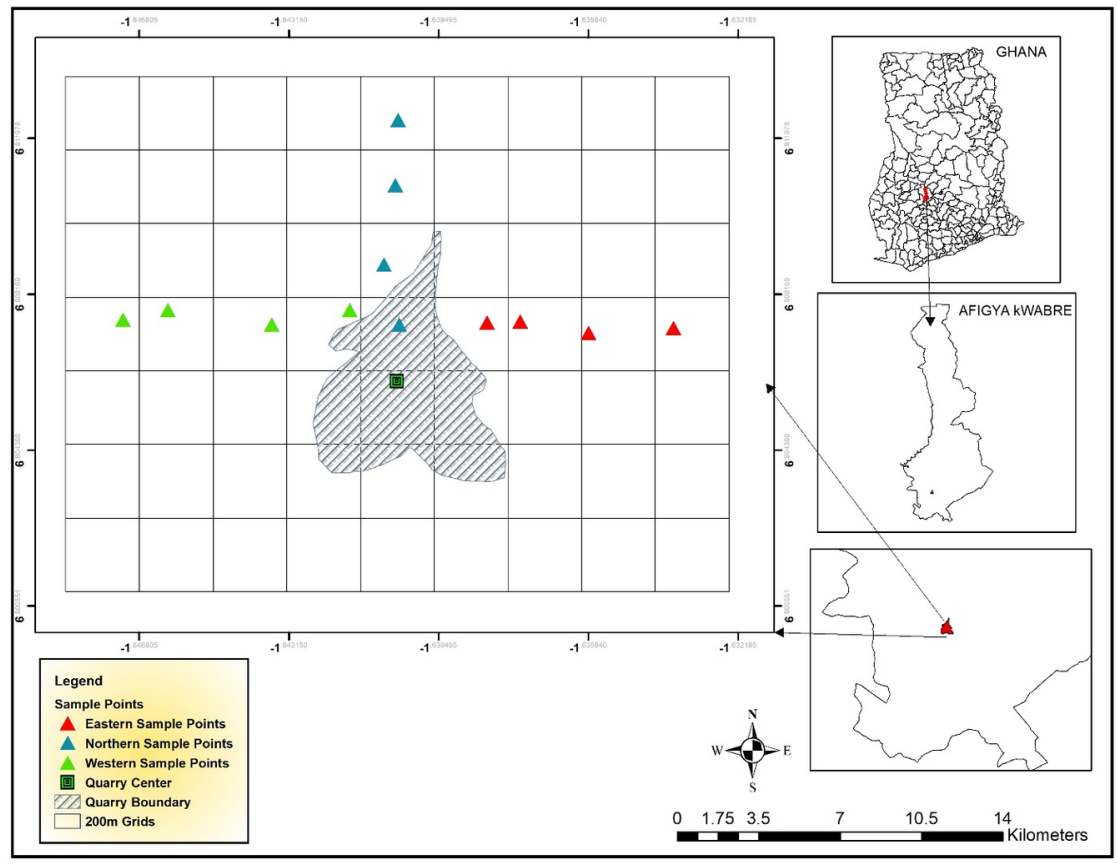

Figure 1: A map showing all the sampling points in all the three zones (Source: Addae, 2019)

Butterfly similarity index 


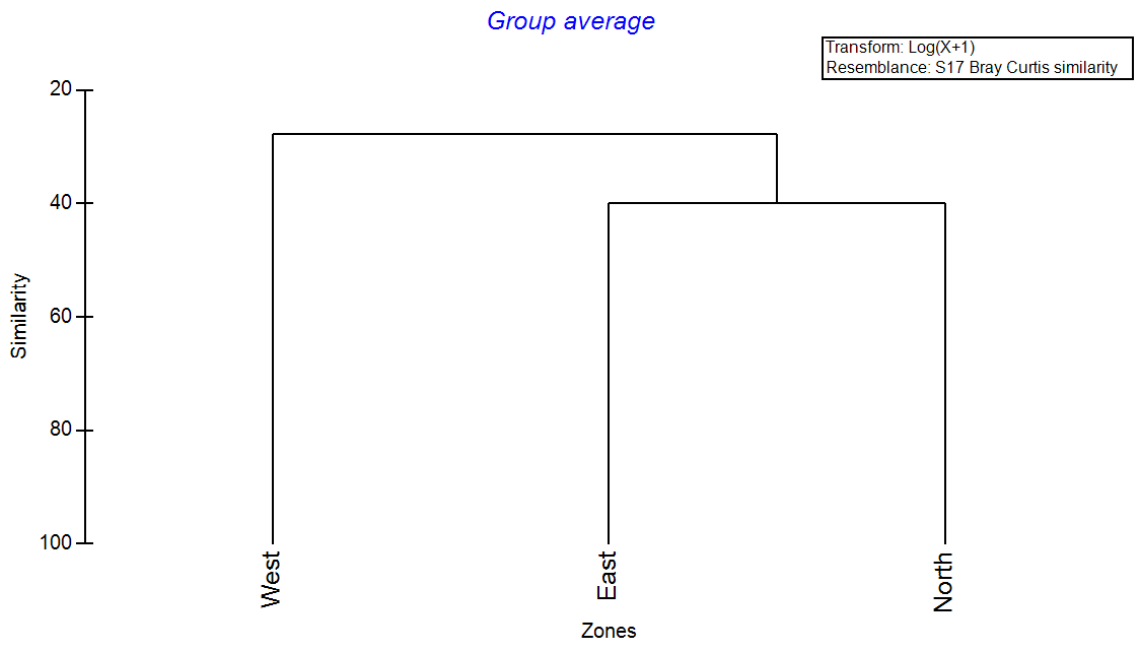

Figure 2: Dendrogram showing similarities of butterflies in the different zones

Table 1: Relative abundance (\%) of butterfly families recorded in all three zones.

Family Eastern Western Northern Total

NYMPHALIDAE 66 (20.1\%) 25 (61.0\%) 15(32.0\%) 106(25.4\%)

PAPILIONIDAE $11(3.3 \%) 1(2.4 \%) 9(19.1 \%) 21(5.0 \%)$

PIERIDAE 101 (30.7\%) 6 (14.6\%) 16 (34.0\%) 123(29.5\%)

HESPERIIDAE $10(3.0 \%) 4(9.8 \%) 3(6.4 \%) 17(4.1 \%)$

LYCAENIDAE $141(42.9 \%) 5(12.2 \%) 4(8.5 \%)$ 150(36.0\%)

\section{Total 3294147417}

Table 2: Diversity indices of butterflies recorded in all three zones.

Diversity index Eastern Western Northern

H' 2.6162 .8072 .696

D 0.82180 .92090 .9072

J' 0.65290 .9080 .8855

d 9.3175 .6555 .195

N 3294147

S 552221

*Simpson index (D), Shannon-Weiner diversity index (H'), Pielou evenness (J'), Margalef (d), Number of individuals $(\mathrm{N})$ and Number of species / species richness (S).

\begin{tabular}{|c|c|c|c|c|c|c|c|c|}
\hline \multirow{2}{*}{$\begin{array}{l}\text { Species } \\
\text { Antiaris toxicaria }\end{array}$} & & \multicolumn{2}{|c|}{ East } & \multicolumn{2}{|c|}{ West } & \multicolumn{2}{|c|}{ North } & \multirow{2}{*}{$\frac{\text { Total }}{8(2.1 \%)}$} \\
\hline & & 4 & $(2.3 \%)$ & 0 & 0 & 4 & $(2.3 \%)$ & \\
\hline Albizia adianthifolia & & 1 & $(0.6 \%)$ & 0 & 0 & 9 & $(5.1 \%)$ & $10(2.6 \%)$ \\
\hline Albizia zygia & & 6 & $(3.4 \%)$ & 0 & 0 & 2 & $(1.1 \%)$ & $8(2.1 \%)$ \\
\hline Amphimas pterocarpoides & Amphimas pterocarpoides & 2 & $(1.1 \%)$ & 0 & 0 & 0 & 0 & $2(0.5 \%)$ \\
\hline
\end{tabular}




\begin{tabular}{|c|c|c|c|c|c|c|c|}
\hline Species & East & & West & & Nortl & & Total \\
\hline Baphia nitida & 30 & $(17.1 \%)$ & 10 & $(9.0 \%)$ & 0 & 0 & $40(10.4 \%$ \\
\hline Baphia pubescens & 10 & $(5.7 \%)$ & 3 & $(2.7 \%)$ & 8 & $(4.6 \%)$ & $21(5.4 \%)$ \\
\hline Blighia sapida & 1 & $(0.6 \%)$ & 0 & 0 & 0 & 0 & $1(0.3)$ \\
\hline Ficus sur & 7 & $(4.0 \%)$ & 0 & 0 & 0 & 0 & $7(1.8 \%)$ \\
\hline Ficus exasperata & 11 & $(6.3 \%)$ & 11 & $(10.0 \%)$ & 21 & $(12.0 \%)$ & $43(11.1 \%$ \\
\hline Margaritaria discoidea & 1 & $(0.6 \%)$ & 22 & $(19.8 \%)$ & 0 & 0 & $23(6.0 \%)$ \\
\hline Millettia zechiana & 9 & $(5.1 \%)$ & 0 & 0 & 0 & 0 & $9(2.3 \%)$ \\
\hline Morinda lucida & 5 & 2.857143 & 17 & $(15.3 \%)$ & 3 & $(1.7 \%)$ & $25(6.5 \%)$ \\
\hline Newbouldia laevis & 0 & 0 & 0 & 0 & 6 & $(3.4 \%)$ & $6(1.6 \%)$ \\
\hline Broussonetia papyrifera & 6 & $(3.4 \%)$ & 18 & $(16.2 \%)$ & 11 & $(6.3 \%)$ & $35(9.05)$ \\
\hline Chromolaena odorata & 25 & $(14.3 \%)$ & 0 & 0 & 0 & 0 & $25(6.5 \%)$ \\
\hline Elaeis guineensis & 55 & $(31.4 \%)$ & 7 & $(6.3 \%)$ & 16 & $(9.1 \%)$ & $78(20.2 \%$ \\
\hline Pseudospondias microcarpa & 2 & $(1.1 \%)$ & 2 & $(1.8 \%)$ & 0 & 0 & $4(1.0 \%)$ \\
\hline Leucaena leucocephala & 0 & 0 & 4 & $(3.6 \%)$ & 0 & 0 & $4(1.0 \%)$ \\
\hline Spondias mombin & 0 & 0 & 2 & $(1.8 \%)$ & 0 & 0 & $2(0.5 \%)$ \\
\hline Cocos nucifera & 0 & 0 & 0 & 0 & 10 & $(5.7 \%)$ & $10(2.6 \%)$ \\
\hline Caragana arborescens & 0 & 0 & 0 & 0 & 4 & $(2.3 \%)$ & $4(1.0 \%)$ \\
\hline Citrus medica & 0 & 0 & 12 & $(10.8 \%)$ & 0 & 0 & $12(3.1 \%)$ \\
\hline Mangifera indica & 0 & 0 & 2 & $(1.8 \%)$ & 4 & $(2.3 \%)$ & $6(1.6 \%)$ \\
\hline Tectona grandis & 0 & 0 & 0 & 0 & 2 & $(1.1 \%)$ & $2(0.5 \%)$ \\
\hline Alstonia boonei & 0 & 0 & 1 & $(1.0 \%)$ & 0 & 0 & $1(0.3 \%)$ \\
\hline Total & 175 & & 111 & & 100 & & 386 \\
\hline
\end{tabular}

Table 3 . Relative abundance of plant species captured in all three zones for both seasons

Table 4 : Diversity indices of plant species for all the three zones.

Diversity index Eastern Western Northern

H’ 2.1732 .2411 .992

N 175111100

S 161313

* Shannon-Weiner diversity index (H'), Number of individuals (N) and Number of species / species richness (S). 